\title{
Chemical Modification of Poly(Vinyl Chloride) Resin to Improve the Photostability Processes
}

\author{
Adel Kamil \\ Iraqi Ministry of Foreign Affairs, Baghdad-Iraq.
}

\begin{abstract}
The photostability of PVC films phenylphrine $\mathrm{HCl}$ acid complexes was investigated. PVC reacts with phenyl phrine $\mathrm{HCl}$ acid (L) in THF to prepare PVC-L compound, which characterized by various spectroscopic methods. PVC-L has been reacted with different metal ions to form PVCL-M ${ }^{\mathrm{II}}$ complexes. The structures of these complexes were characterized by IR and Uv-Vis. Spectrophotometry. The photostabilization activity of these compounds was determined by monitoring different indices with irradiation time. The changes in viscosity average molecular weight $\left(\overline{\mathrm{M}}_{\mathrm{v}}\right)$ of PVC with irradiation time were also confirmed (using THF as a solvent). The quantum yield of the chain scission (Фcs) of modified polymer films was evaluated and found to range between $4.990 \times 10^{3}$ and $1.147 \times 10^{4}$. Surface morphology of the films was studied by atomic force microscope (AFM). All results show that the rate of photodegradation of PVC-L-M ${ }^{\mathrm{II}}$ films following the trends: PVC- L- Cd ${ }^{\mathrm{II}}<$ PVC- L- $\mathrm{Zn}^{\mathrm{II}}<$ PVC- L-Cu ${ }^{\mathrm{II}}<$ PVC- L-Co ${ }^{\mathrm{II}}<$ PVC- L $<$ PVC. According to the experimental results obtained several mechanisms were indicated depending on the structure of the PVC-L-M ${ }^{\mathrm{II}}$ complexes. [DOI: 10.22401/ANJS.21.4.01]
\end{abstract}

Keywords: PVC films; AFM; photostability; Metal ions, Uv Light.

\section{Introduction}

All generally utilized plastics degrade under the effect of sunlight and which why the polymers photostability is the most remarkable properties [1]. Because of all types of Polymeric materials such as semisynthetic, synthetic and natural are not pure compounds. so, these compounds are photodegradable when exposed to the environment. For example, they ordinarily consist of additives (e.g., fillers, pigments, stabilizers, finishing agents) and impurities (e.g., catalyst residues, oxidation products,) that may good effect or even control the photochemistry of polymeric system [2].

Poly(vinyl chloride) and its abbreviation PVC, is one of the most multilateral plastics [3]. It is the second largest fabricated resin by volume worldwide. Among the five kinds of general plastic materials, PVC is second only to polyethylene, which was quite used in industries including electronic, chemical engineering, architecture, transportation and packaging [4]. In the wavelength range (200-700)nm, PVC has a poor light stability, perhaps attribute to the presence of unsaturated $\mathrm{C}=\mathrm{C}$ bonds, hydroxy, hydroperoxide, and carbonyl groups in the polymeric chains [5]. Several stabilizing systems can be used to protect plastic materials against UV radiation. Ultraviolet Light Absorbers, Quenchers or Energy Transfer Agents, as well as Hindered Amine Light Stabilizers are the most important types of photostabilizers [6]. The UV absorber contends with all chromophores in the figuration and scatters the absorbed energy as heat [7].

\section{Experimental}

\subsection{Instrumentation}

All starting materials and solvents were purchased and used without purification. The Fourier transformed infrared spectroscopy (FTIR) spectra using the $\mathrm{KBr}$ disc on FTIR 8300 Shimadzu spectrophotometer were obtained in the range (4000-400) $\mathrm{cm}^{-1}$. Shimadzu UV- Vis 160 A- Ultravioletvisible spectrophotometer were used to measure UV- vis. Spectra in the range (2001100)nm.

\subsection{Synthesis of PVC ligand complex}

Metal complexes of poly(vinyl chloride) phenyl prime $\mathrm{HCl}$ were synthesized according to a reported procedure [8]. Fig. (1), shows the structure of PVC-L-M ${ }^{\mathrm{II}}$ polymer. 


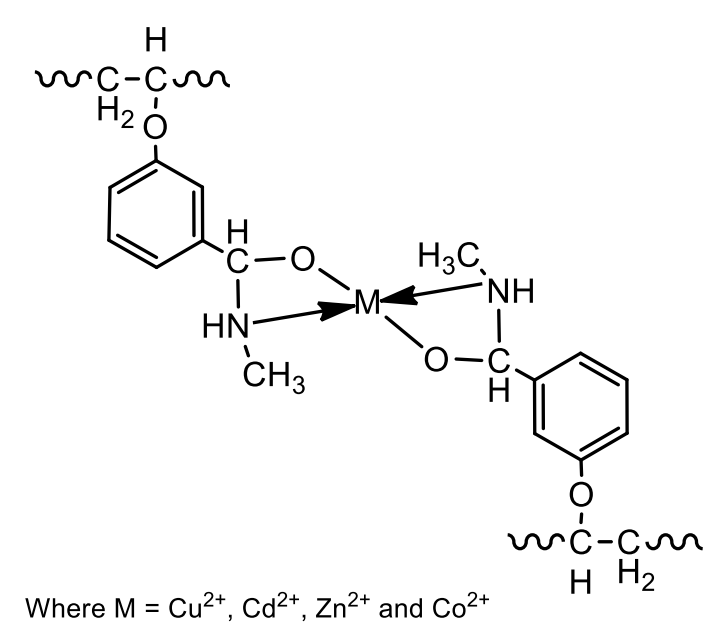

Fig. (1): Structures of metal complexes.

\subsection{Purification of Poly(vinyl Chloride)}

Poly(vinyl chloride) was re-precipitated in ethanol from tetrahydrofuran (THF) solution to purify, then dried at room temperature under reduced pressure for $24 \mathrm{~h}$.

\subsection{Films preparation}

$(5 \mathrm{~g})$ of PVC was dissolved in $(100 \mathrm{~mL})$ of THF, A solution was mixed for $30 \mathrm{~min}$ at room temperature. PVC-L-M ${ }^{\mathrm{II}}(0.5 \mathrm{wt} \%)$ were added to PVC mixture, the solution was stirred at room temperature for $30 \mathrm{~min}$. The solution was cast onto glass plate to evaporate the solvent. The PVC films thickness (40 micrometer) measured by a micrometer type 2610 A, Germany.

\subsection{Accelerated testing technique}

Accelerated weather-meter QUV tester (QPanel Company, Homestead, FL, USA) was carried out to Irradiate PVC films. It supplied with a UV-B 313 fluorescent ultraviolet lamp $(40 \mathrm{~W})$ at each side, the spectrum range (290360) $\mathrm{nm}$ in which maximum wavelength was fixed at $313 \mathrm{~nm}$ [9].

\subsection{Photodegradation measuring methods}

\subsubsection{Measuring the photodegradation rate}

of polymer films using infrared spectrophotometry

The photodegradation degree of polymeric films was monitored by FTIR 8300 Shimadzu Spectrophotometer $\left(400-4000 \mathrm{~cm}^{-1}\right)$ in which of polyene, hydroxyl and carbonyl groups absorption occur at 1602, 3500 and $1722 \mathrm{~cm}^{-1}$ respectively. The changes in these absorption peaks indicated the photodegradation progress at different irradiation times, The comparison between the FTIR polyene, hydroxyl and carbonyl groups absorption peaks and the reference peak $\left(1328 \mathrm{~cm}^{-1}\right)$ allow the calculation of the polyene $\left(\mathrm{I}_{\mathrm{PO}}\right)$, hydroxyl $\left(\mathrm{I}_{\mathrm{OH}}\right)$ and carbonyl $\left(\mathrm{I}_{\mathrm{CO}}\right)$ indices [10] as shown in Equation 1

$$
I_{S}=\frac{A_{s}}{A_{r}}
$$

Where

$I_{\mathrm{S}}=$ the index of group under study

$\mathrm{A}_{\mathrm{s}}=$ absorbance peak

$\mathrm{A}_{\mathrm{r}}=$ reference peak absorbance .

The difference between the absorbance of base line and top (A Top Peak - A Base Line) is known as the actual absorbance and calculated by the Base Line method [11].

\subsubsection{Determination of average molecular} weight $\left(\overline{\mathrm{M}}_{\mathrm{v}}\right)$ using viscometry method

The polymer average molecular weight was determined in terms of the viscosity property by Mark-Houwink relation [12].

$$
[\eta]=K \bar{M}_{v}^{\alpha}
$$

Where $[\eta]=$ the intrinsic viscosity, $\alpha$ and $\mathrm{K}=$ constants which depend on the polymersolvent system. The intrinsic viscosity of polymer solution was determined by Ostwald U-Tube Viscometer. The flow times of pure solvent and polymer solution are $\mathrm{t}_{0}$ and $\mathrm{t}$, respectively. To calculate the specific viscosity $\left(\eta_{\mathrm{sp}}\right)$ Equation 3 was used.

$$
\eta_{\mathrm{re}}=\frac{\mathrm{t}}{\mathrm{t}_{\mathrm{o}}}
$$

Where $\eta_{\mathrm{re}}=$ the relative viscosity.

$$
\begin{aligned}
& \eta_{\mathrm{sp}}=\eta_{\mathrm{re}-1} \\
& {[\eta]=(\sqrt{2} / \mathrm{c})\left(\eta_{\mathrm{sp}}-\ln \eta_{\mathrm{re}}\right)^{1 / 2} .}
\end{aligned}
$$

Where $\mathrm{C}=$ concentration of polymeric solution $(\mathrm{g} / 100 \mathrm{ml})$. The main chain scission quantum yield $\left(\Phi_{\mathrm{cs}}\right)$ [13], was calculated from the viscosity measurement by the use of Equation 6.

$$
\left.\phi_{\mathrm{cs}}=\left(\mathrm{CA} / \overline{\mathrm{M}}_{\mathrm{v}, \mathrm{o}}\right) \mid\left(\left[\eta_{\mathrm{o}}\right] /[\eta]\right)^{1 / \alpha}-1\right] / \mathrm{I}_{\mathrm{o}} \mathrm{t}
$$


Where $\mathrm{A}=$ Avogadro's number, $\mathrm{C}=$ Concentration, $\left(\overline{\mathrm{M}}_{\mathrm{v}, \mathrm{o}}\right)=$ Initial viscosityaverage molecular weight, $\mathrm{I}_{\mathrm{O}}=$ incident intensity, $\mathrm{t}=$ Irradiation time in second and $\left[\eta_{\mathrm{o}}\right]=$ intrinsic viscosity of PVC before irradiation.

\section{Result and discussion}

\subsection{FTIR Spectroscopy for PVC Films}

Poly(vinyl chloride)-Phenylephrine $\mathrm{HCl}$ $\mathrm{Co}(\mathrm{II}), \mathrm{Cu}(\mathrm{II}), \mathrm{Zn}$ (II) and $\mathrm{Cd}(\mathrm{II})$ complexes were used to modification the PVC photostability. The photochemical activity of these PVC-complexes films were studied, the polyene, hydroxyl and carbonyl indices with irradiation time were monitored using IR spectrophotometry. The absorption bands appeared at 1722,1602 and $3500 \mathrm{~cm}^{-1}$ were attributed to the formation of the carbonyl, polyene and hydroxyl groups respectively [14]. The FTIR spectra of PVC (control) during irradiation are shown in Fig.(2).

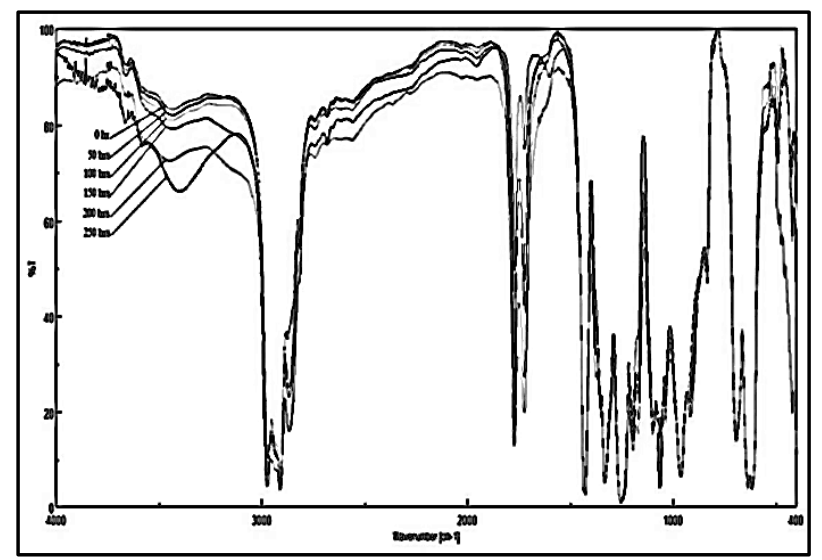

Fig. (2): Changes in FTIR spectra of PVC

film (control) at different irradiation.
To follow extend of polymer degradation during irradiation, the absorption of carbonyl, polyene and hydroxyl groups are used. Therefore, the growth of indices is a measure to extent of degradation. the presence of PVC- L- Co ${ }^{\text {II }}$ PVC- L- Cu ${ }^{\text {II }}$ PVC- L-Zn ${ }^{\text {II }}$, PVC- L-Cd ${ }^{\text {II }}$ and PVC- L with respect to PVC film (control) show lower growth rate of carbonyl index with irradiation time.

As shown in Fig.(3-5), the growth of $I_{\mathrm{CO}}$, $I_{\mathrm{PO}}$ and $I_{\mathrm{OH}}$ upon irradiation time is less than PVC (control). So, these PVC-complexes observed as PVC photostabilizers. The efficient photostabilizer view a longer induction period. So, the PVC-L-Co (II) is the most effective photostabilizer, followed by PVC- L- Cu(II), PVC- L-Zn(II), PVC- LCd(II), PVC- L and PVC.

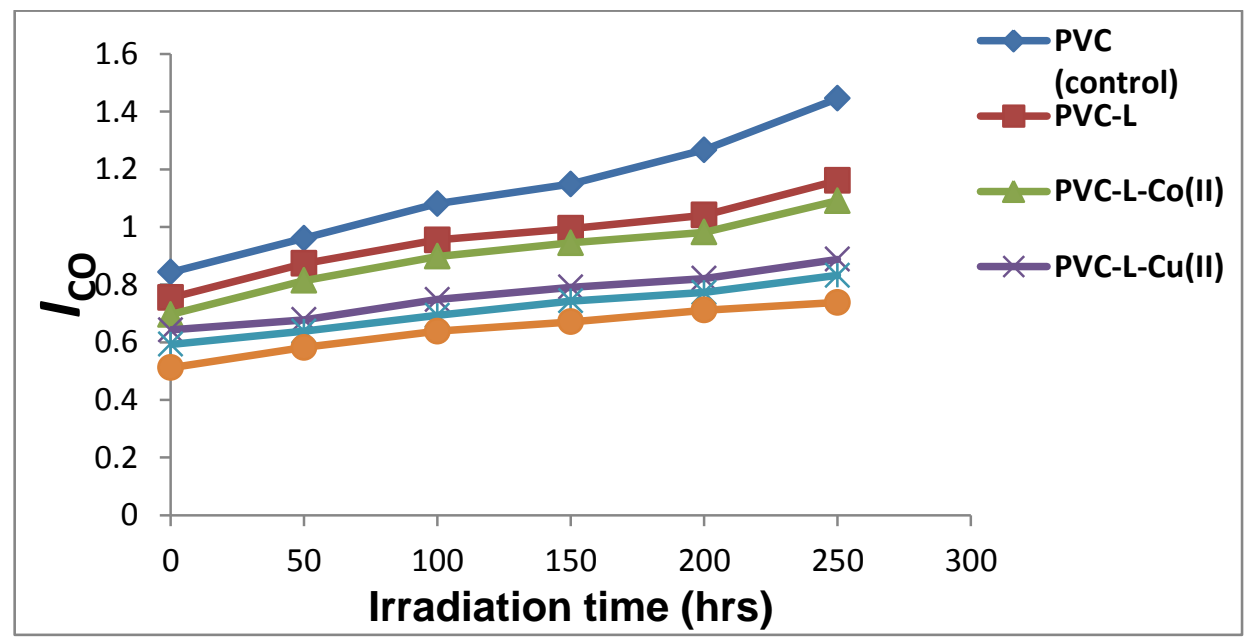

Fig. (3): The relationship between $I_{C o}$ and irradiation time for PVC-L-M(II) films. 


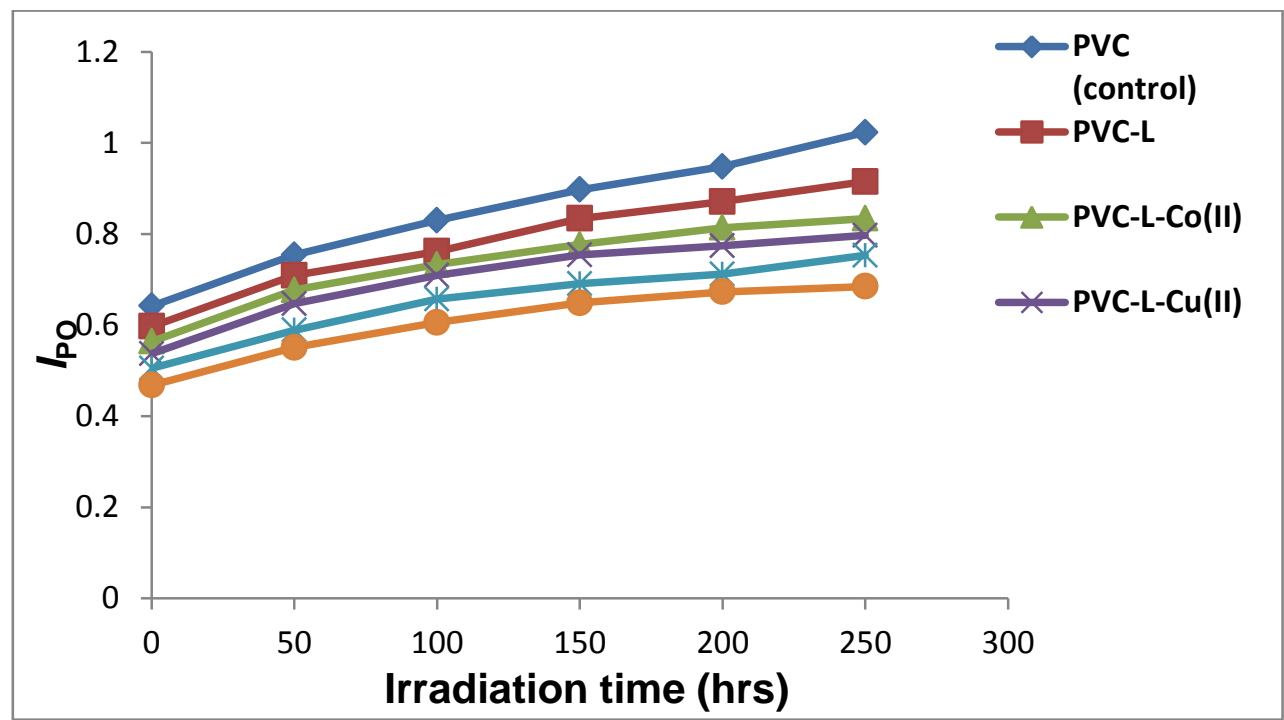

Fig. (4): The relationship between IPo and irradiation time for PVC-L-M(II) films.

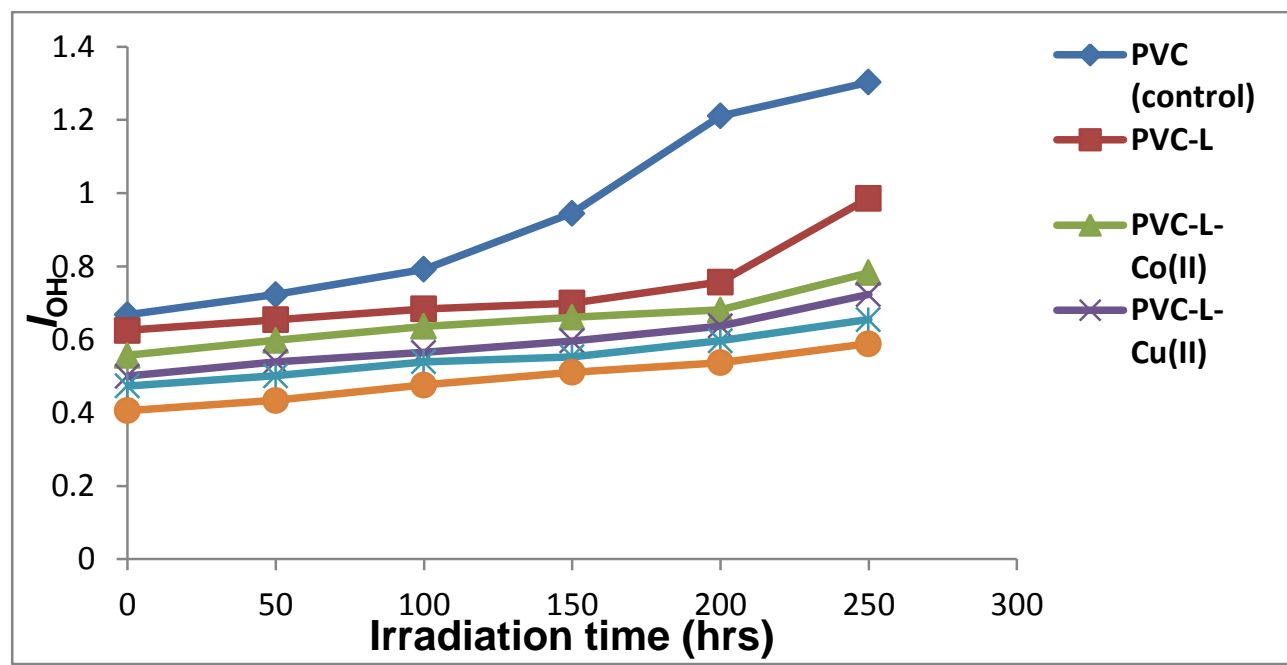

Fig. (5): The relationship between $I_{O H}$ and irradiation time for PVC-L-M(II) films.

\subsection{Variation of PVC molecular weight} during photolysis

A versatile test for random chain scission was provided from the analysis of the relative changes in viscosity average molecular weight $\left(\overline{\mathbf{M}}_{\mathrm{v}}\right)$. Fig.(6) shows the changes in $\overline{\mathbf{M}} \mathbf{v}$ against irradiation time for PVC (control) and PVC-complex at a light absorption intensity of $6.02 \times 10^{-9}$ einstein $\mathrm{dm}^{-3} \mathrm{sec}^{-1}$.

To measure $\overline{\mathbf{M}} \mathbf{v}$, Equation 3 was used at room temperature. It is importance indicating that insoluble film traces suggest that some degree of branching PVC or cross-linking occur during photolysis process [15]. To confirm that, Equation 7 was used to calculate the number of average chain scission $(S)[16]$.

$$
\mathrm{S}=[\overline{\mathrm{Mv}}, \mathrm{o} / \overline{\mathrm{Mv}}, \mathrm{t}]-1
$$

Where $\overline{\mathrm{Mv}}, \mathrm{o}$ and $\overline{\mathrm{Mv}}, \mathrm{t}=$ the viscosity average molecular weight at initial (0) and $t$ irradiation time, respectively. Fig.(7) shows $\mathrm{S}$ with irradiation time and indicates an increase in the branching degree that might arise from cross-linking. The insoluble residue formed during the irradiation process provides an additional evidence for the cross-linking occurrence. Randomly distributed weak bonds [17], are break rapidly in the initial stages of photodegradation. Equation 8 was used to calculate the degree of deterioration $(\alpha)$.

$$
\alpha=M \times S / \bar{M} v
$$

Where $\mathbf{M}=$ the initial molecular weight. Fig.(8) shows the $\alpha$ with irradiation time. $\alpha$ values for the irradiated films are higher for PVC (control) and lower to the modified polymer. The value of $\alpha$ increases with time in 
the first stages of PVC photodegradation

which is an indication of random polymeric

chain bonds breaking.

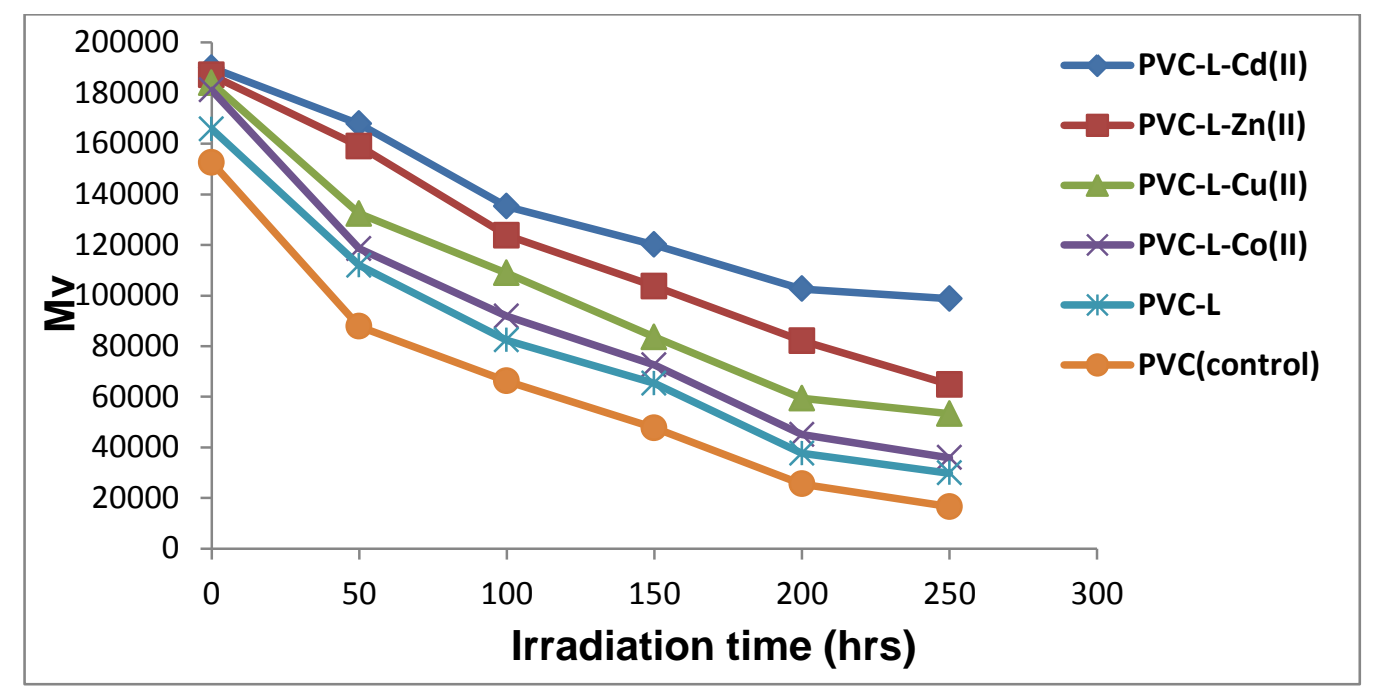

Fig. (6): Changes in the viscosity average molecular weight (Mv) during irradiation of PVC

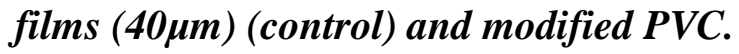

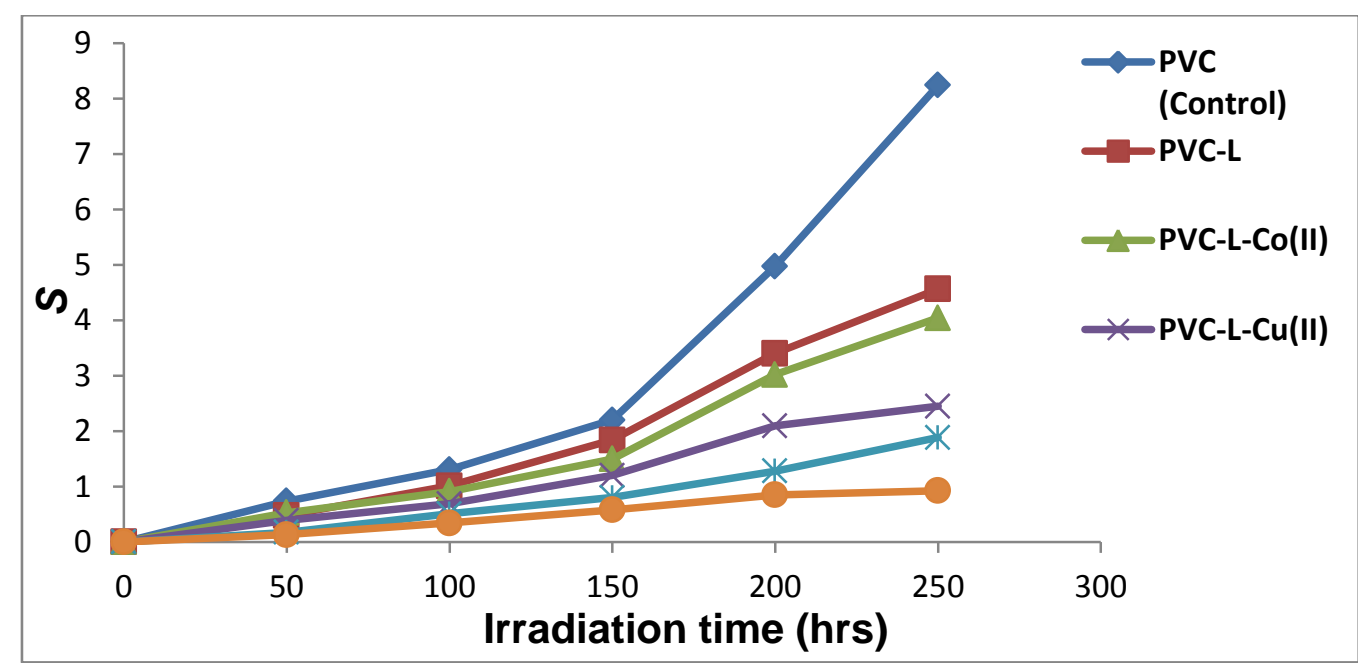

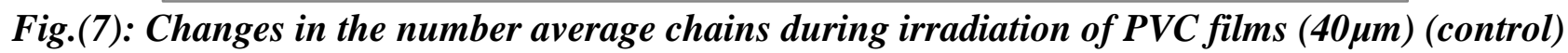
and modified PVC films.

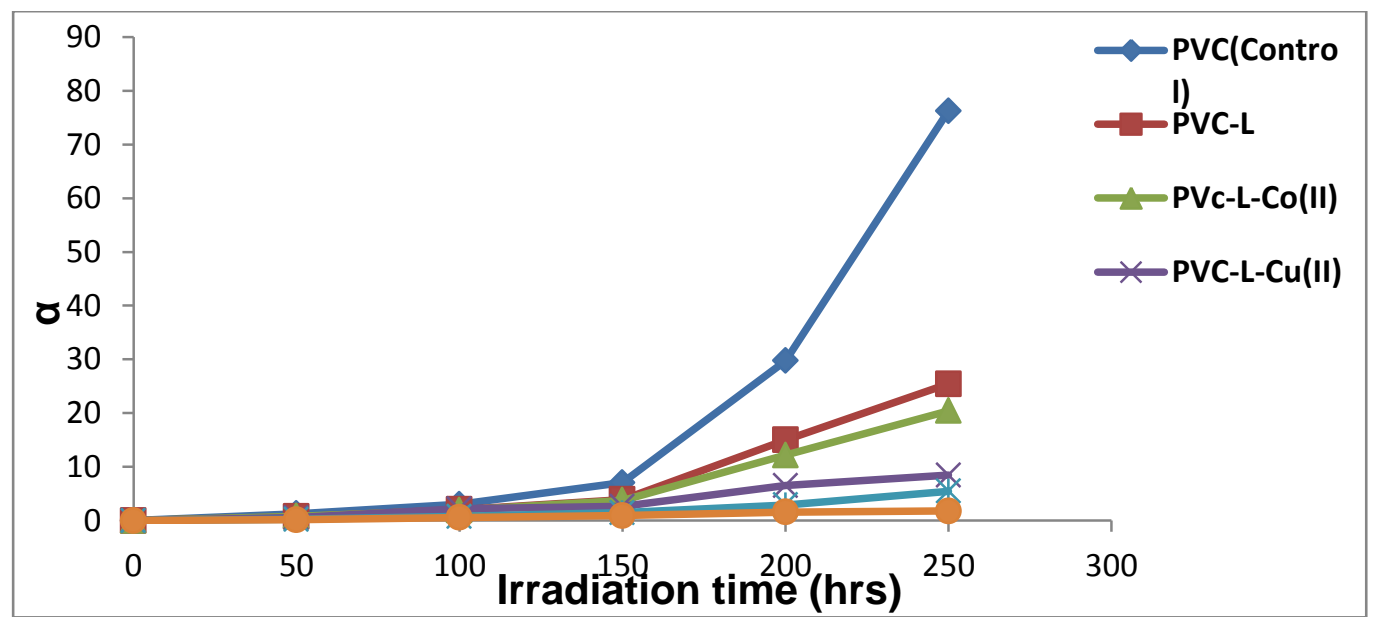

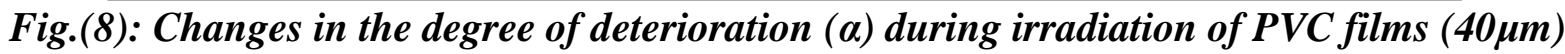
(control) and modified PVC films. 
From the quantum yield of the chain scission $\left(\Phi_{\mathrm{cs}}\right)$ measurements could be obtained other evidence for the degradation reaction. The quantum yield for PVC-complex films was calculated from Equation (6). The low values of $\Phi_{c s}$ can be illustrated that in PVC macromolecule, the energy was absorbed at one site, and the electronic excitation is spread over several bonds so that the prospect of a breaking single bond is low, or the absorbed energy is wasted by non-reactive processes. The $\Phi_{\mathrm{cs}}$ values for PVC-complex are given in Table (1).

\section{Table (1)}

Quantum yield $\left(\Phi_{c s}\right)$ for PVC films (40 $\mu m$

thickness) after irradiation time $(250 \mathrm{~h})$.

\begin{tabular}{||c||c|}
\hline Sample & $\begin{array}{c}\text { Quantum yield of main } \\
\text { chain scission (Фcs) }\end{array}$ \\
\hline \hline PVC (control) & $4.99 \mathrm{E}-03$ \\
\hline PVC-L & $4.79 \mathrm{E}-03$ \\
\hline PVC-L-Co (II) & $3.38 \mathrm{E}-03$ \\
\hline PVC-L-Cu (II) & $3.68 \mathrm{E}-04$ \\
\hline PVC-L-Zn (II) & $1.66 \mathrm{E}-04$ \\
\hline \hline PVC-L-Cd (II) & $1.14 \mathrm{E}-04$ \\
\hline
\end{tabular}

The $\Phi_{\mathrm{cs}}$ values for PVC-complex are less than that for the corresponding ones PVC (control) and increases in the order:

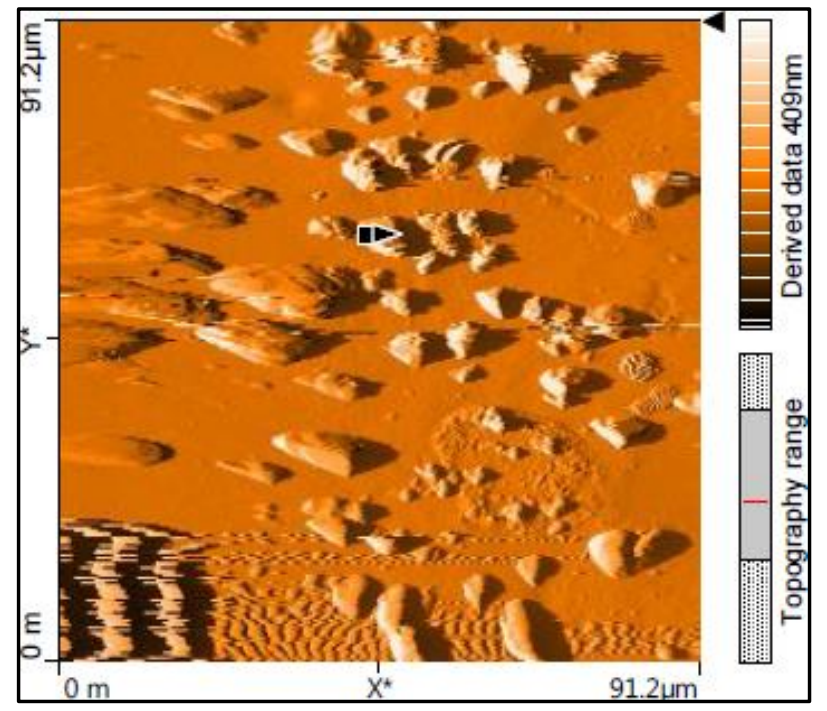

PVC $>$ PVC- L > PVC- L-Co(II) $>$ PVC- L$\mathrm{Cu}(\mathrm{II})>$ PVC- L- Zn(II) $>$ PVC- L- Cd(II).

\subsection{Surface analysis}

Atomic force microscope (AFM) was used to provide information concerning polymer morphology. AFM is good technique to measure the pore size, roughness factor and two and three dimensional topographic images of the samples. Values of roughness factor (Rq) are listed in Table (2). In this study, AFM technique has been utilized to show the two and three dimensional images of prepared films over the scanned area $5.0 \mu \mathrm{m} \times 5.0 \mu \mathrm{m}$. The PVC (control) and PVC-L-Cd (II) sample having the most efficient in photostabilization process was subjected to atomic force microscopic studies and its topographic and three-dimensional images after exposure to UV light are shown in Fig. (9) and (10).

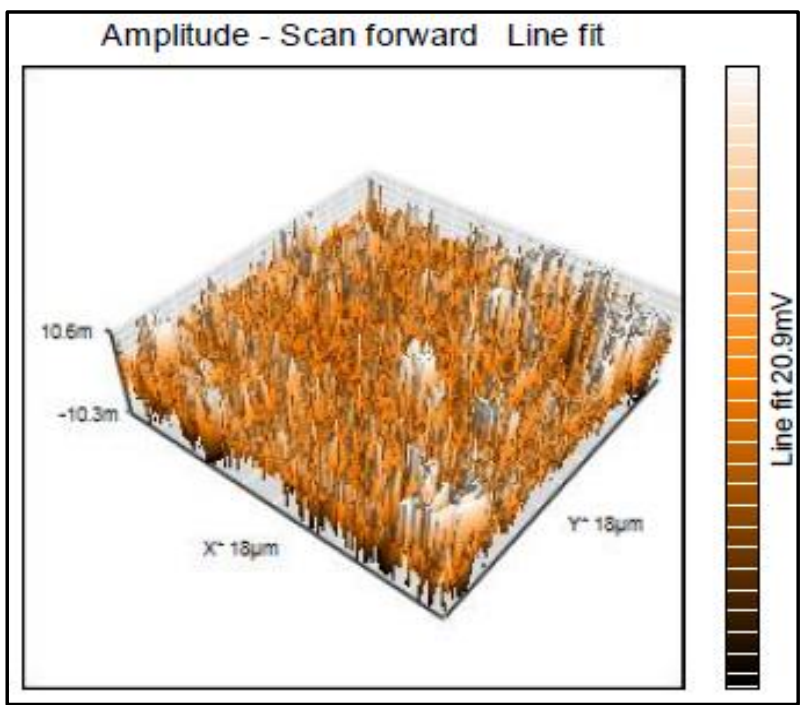

Fig. (9): 2D and 3D of AFM images of PVC (control) film exposed to $250 \mathrm{hrs}$ UV light. 

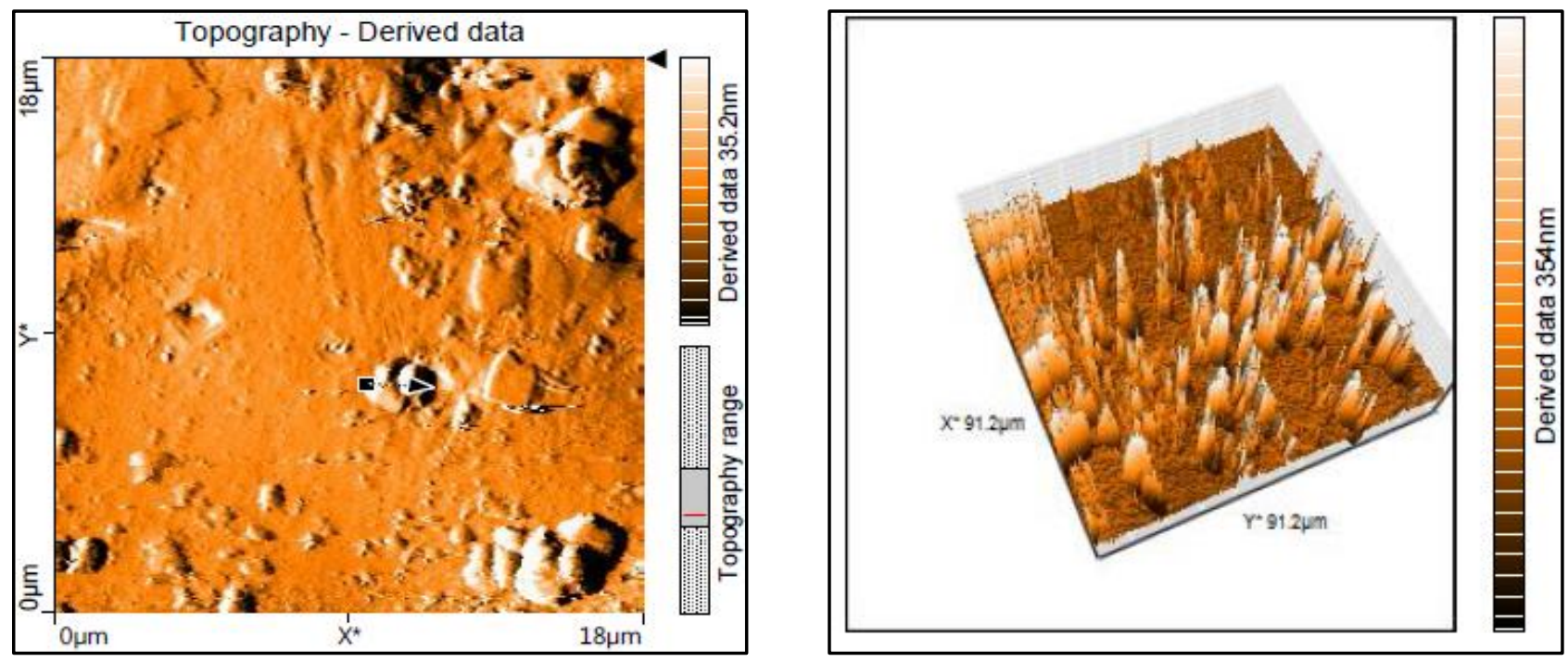

Fig.(10): 2D and 3D of AFM images of PVC-L-Cd (II) film exposed to 250 hrs UV light.

Surface of irradiated PVC-L-Cd (II) film was neat compared to other films $(\mathrm{Rq}=34.8$ $\mathrm{nm}$ ). PVC (control) was highly rough $(\mathrm{Rq}=116.3)$. This can be demonstrate by breaking of bonds after exposure to UV light, removal of leachables from the surface and creating roughness [18].

\section{Table (2)}

$R q$ values of PVC films surface.

\begin{tabular}{||c|c|}
\hline Film & $\mathbf{R q}$ \\
\hline \hline PVC (control) & 116.3 \\
\hline \hline PVC-L-Cd (II) & 34.8 \\
\hline
\end{tabular}

\subsection{Suggested mechanisms of photostabilization process}

Suggested mechanisms of PVC photostabilization by modification through all results obtained,

1. These polymers acting as radical scavengers during energy transfer and by forming unreactive charge transfer complexes between modified polymers, an excited state of chromophore (POO.) and stabilize through resonating structures as shown in scheme (1).

2. Benzene ring in these modified polymers acts a role in the mechanism of the stabilizer process by acting as UV absorber. The UV light absorption by these polymers containing these rings dissipates the UV energy to harmless heat energy scheme (2). Furthermore, this ring play a role in resonating structures conjugation of radical in peroxide decomposer, scheme (2), which support these rings as photostabilizer. 


$$
\begin{aligned}
& \mathrm{PH}(\text { polymer }) \stackrel{\mathrm{h} v}{\longrightarrow} \underset{\mathrm{P}}{ } \stackrel{\dot{\mathrm{H}}}{\longrightarrow}+\mathrm{O}_{2} \longrightarrow
\end{aligned}
$$

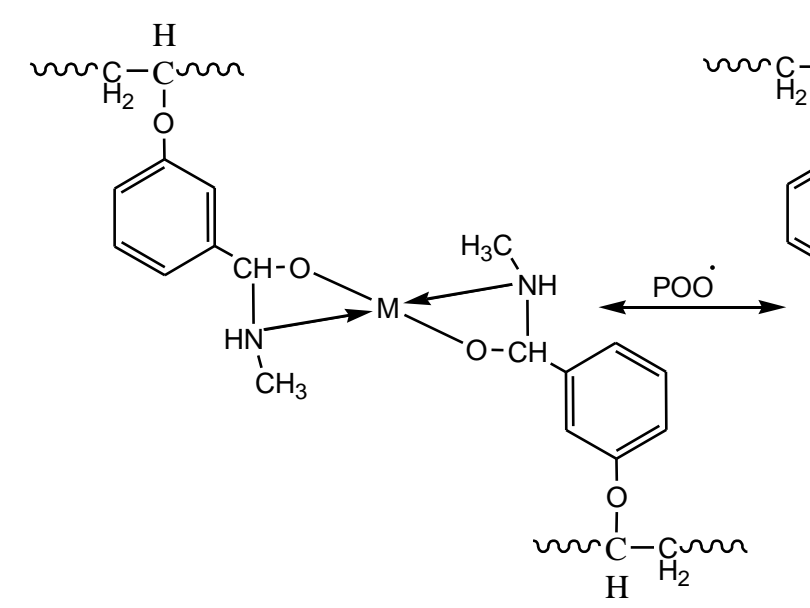

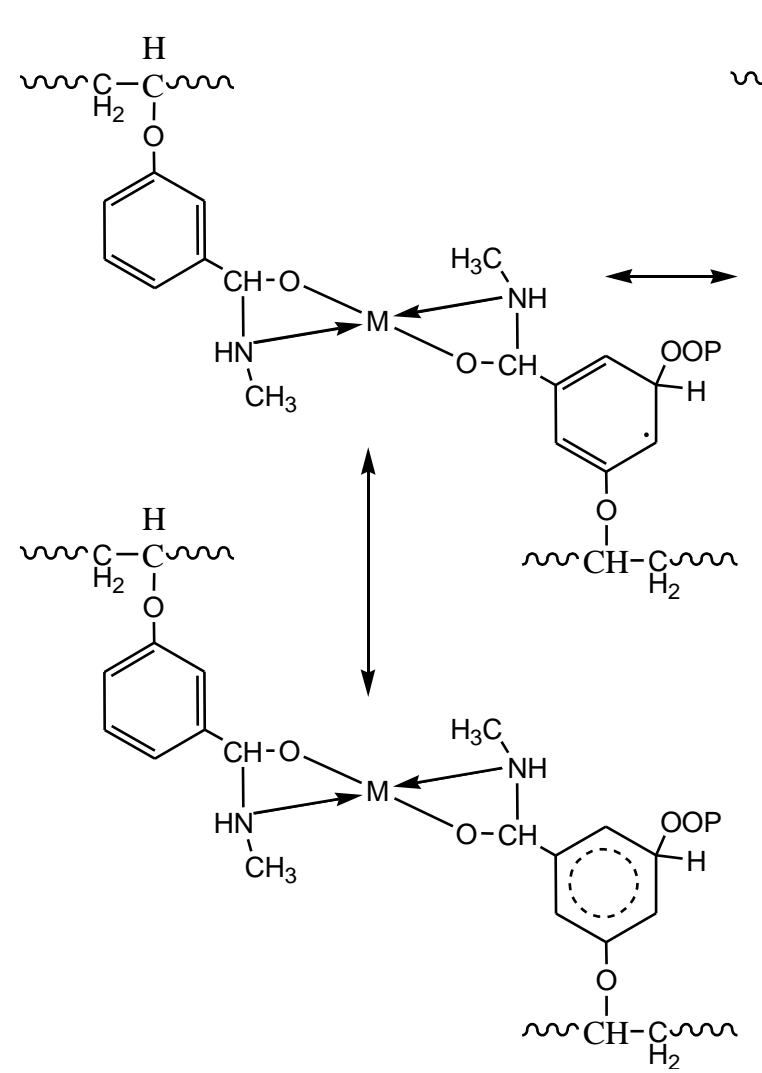

Scheme (1): Suggested mechanism of PVC-L-M (II) photostabilization as radical scavengers.<smiles>CCOc1cccc(C)c1Cc1ccc([18F])cc1C</smiles>

\section{Scheme (2). Suggested mechanism of benzene ring photostabilization as $U V$ absorber.}

\section{Conclusion}

PVC bound phenylphrine $\mathrm{HCl}(\mathrm{L})$ can be prepared by displacement reaction between PVC and the ligand. folowing complexation of
PVC-L with $\mathrm{Cd}$ (II), $\mathrm{Zn}(\mathrm{II}), \mathrm{Cu}(\mathrm{II})$ and $\mathrm{Co}(\mathrm{II})$ yield intensive colored PVC-L-M ${ }^{\mathrm{II}}$ complexes which demonstration better overall photostabilization process. The activity of 
these polymeric complexes in photostabilization which increase in the order:

PVC- L- $\mathrm{Cd}^{\mathrm{II}}>$ PVC- L-Zn ${ }^{\mathrm{II}}>$ PVC- L-Cu ${ }^{\mathrm{II}}$ $>$ PVC- L- Co ${ }^{\text {II }}>$ PVC- L $>$ PVC

\section{References}

[1] Yousif E., Salih N., Salimon J. J., Improvement of the Photostabilization of PVC Films in the Presence of $2 \mathrm{~N}$ Salicylidene-5-(Substituted)-1,3,4-

Thiadiazole, App. Polym. Sci., 120, $2207-$ 2214, 2011.

[2] Balakit A., Ahmed A., El-Hiti G. A., Smith K., Yousif E., Synthesis of New Thiophene Derivatives and Their Use as Photostabilizers for Rigid Poly(vinyl chloride), Int. J. Polym. Sci., 1-10, 2015; http://dx.doi.org/10.1155/2015/510390.

[3] Ahmed D.S., El-Hiti G.A., Hameed A.S., Yousif E., Ahmed A., New Tetra-Schiff Bases as Efficient Photostabilizers for Poly(vinyl chloride), Molecules, 22, 1506, 2017.

[4] Huang Z., Ding A., Guo H., Lu G., Huang, $\mathrm{X}$., Construction of nontoxic polymeric UV-absorber with great resistance UVphotoaging, Sci. Rep., 6, doi:10.1038/srep25508, 2016.

[5] Yousif E., Hameed A., Rashed R., Mansoor H., Farina Y., Graisa A., Salih N. Salimon J., Synthesis and Photostability Study of Some Modified Poly(vinyl chloride) Containing Pendant Benzothiazole and Benzimidozole Ring, Int. J. Chem., 2, 65-80, 2010.

[6] Ahmed D.S., El-Hiti G.A., Hameed A.S., Yousif E., Polyphosphates as Inhibitors for Poly(vinyl Chloride) Photodegradation, Molecules, 22, 1849, 2017.

[7] Yousif E., Hasan A., Photostabilization of poly(vinyl chloride), Journal of Taibah University for Science, 9, 421-448, 2015.

[8] Yousif E., Hasan A., El-Hiti, G. A., Spectroscopic, Physical and Topography of Photochemical Process of PVC Films in the Presence of Schiff Base Metal Complexes, Polymers, 8, 204, 2016.

[9] Yousif E., Yusop R., Ahmed A., Salimon J., Salih N., Photostabilizing efficiency of PVC based on epoxidized oleic acid, Mala. J. Anal. Scie., 19, 213-221, 2015.
[10] Yousif E., Triorganotin(IV) complexes photo-stabilizers for rigid PVC against photodegradation J. Taibah University for Science, 7, 79-87, 2013.

[11] Yousif E., El-Hiti, G.A., Hussain Z., Altaie A., Viscoelastic, Spectroscopic and Microscopic Study of the Photo Irradiation Effect on the Stability of PVC in the Presence of Sulfamethoxazole Schiff's Bases, Polymers, 7, 2190-2204, 2015.

[12] Mark, J. Physical Properties of Polymers Handbook; Springer: New York, NY, USA, 2007.

[13] Yousif E., Salimon J., Salih N., New stabilizers for polystyrene based on $2-\mathrm{N}$ salicylidene-5-(substituted)-1,3,4-

thiadiazole compounds, J. King Saud University, 24, 299-306, 2012.

[14] Yousif E., Al-Amiery A.A., Kadihum A., Kadhum A.H., Mohamad A.B., Photostabilizing Efficiency of PVC in the Presence of Schiff Bases as Photostabilizers, Molecules, 20, 1988619899, 2015.

[15] Yousif E., Hameed A., Salih N., Salimon J., Abdullah B., New photostabilizers for polystyrene based on 2,3-dihydro-(5mercapto-1,3,4-oxadiazol-2-yl)-phenyl-2(substituted)-1,3,4-oxazepine- 4,7-dione compounds, SpringerPlus Journal, 2, 104, 2013.

[16] Scott, G. Polymers and Ecological Problems; Plennm Press: New York, NY, USA, 1973; Volume 3, pp. 27-35.

[17] Ali G.Q., El-Hiti G.A., Tomi I.H.R., Haddad R., Al-Qaisi A.J., Yousif E., Photostability and Performance of Polystyrene Films Containing 1,2,4Triazole-3-thiol Ring System Schiff Bases, Molecules, 21, 1699, 2016.

[18] Ali M.M., El-Hiti G.A., Yousif E., Photostabilizing Efficiency of Poly(vinyl chloride) in the Presence of Organotin(IV) Complexes as Photostabilizers, Molecules, 21, 1151, 2016. 